\title{
A Hyperbolic Model of Optimal Cash Balances ${ }^{1}$
}

\author{
John van der Burg ${ }^{*}$, Xiaojing Song ${ }^{c}$, Mark Tippett ${ }^{\$}$ \\ *Nelson Marlborough Institute of Technology, Hardy Street, Nelson, 7010, New Zealand \\ ${ }^{\mathbf{c}}$ Norwich Business School, University of East Anglia NR4 7TJ, UK \\ \$ Business School, University of Sydney, Codrington Street, NSW, 2008, Australia \\ \#Victoria Business School, Victoria University of Wellington, New Zealand
}

\begin{abstract}
We develop a hyperbolic cash management model based on the Pearson Type IV probability density which minimises extreme variations in firm cash balances. Since the moments for the Type IV probability density are in general undefined and maximum likelihood estimation is compromised by the non-algebraic nature of the Type IV normalising constant, parameter estimation is implemented using the $\chi^{2}$ minimum method. Empirical analysis shows that the Type IV density is highly compatible with the quarterly cash flow data of a randomly selected sample of 100 large U.S. corporations. In contrast, around sixty per cent of the 100 corporations return Jarque-Bera test statistics which are incompatible with the Gaussian probability density.
\end{abstract}

Key Words: Cash balance; Hyperbolic; Hamilton-Jacobi-Bellman equation; Pearson Type IV probability density.

\footnotetext{
${ }^{1}$ The authors gratefully acknowledge the very helpful suggestions and criticisms of the Editor and referees.
} 


\section{Introduction}

Much has been written on the issue of determining optimal cash holdings by firms. The seminal work is that of Miller and Orr (1966) and is based on the assumption that firm cash balances evolve in terms of a pure random walk (Karlin and Taylor 1981, 342). Doubts about the empirical validity of the random walk assumption have been expressed by a number of authors (Tapiero and Zuckerman 1980; Higson et al. 2010; da Costa Moraes et al. 2015; Wang et al. 2018), including Miller and Orr $(1966,430)$ themselves. Hence, our purpose here is to propose and then empirically validate a more general cash management model based on hyperbolic cash flows and probabilities. ${ }^{2}$

We commence our analysis in the next section with a brief summary of the prior literature. In section 3 we follow Miller and Orr (1966) in assuming firms implement cash management policies which minimise the likelihood of their productive processes being disrupted by extreme variations in their cash balances. ${ }^{3}$ Here, cash injections and withdrawals are used to minimise the expected integral sum of the discounted squared cash balances held by the firm over time. The optimal control for cash injections and withdrawals is then determined using the Hamilton-Jacobi-Bellman fundamental equation of optimality based on Bartlett's general polynomial representation of a diffusion process (Cox and Miller 1965, 218). We show in particular that in unconditional form, a truncated interpretation of Bartlett's representation leads to cash flows that evolve in terms of the Pearson Type IV probability density (Leonenko and Phillips 2012, 2866; Grigelionis 2013, 67; Shaw and Schofield 2015, 983984). In section 4 we address the issue of parameter estimation - something which Kendall and Stuart $(1977,163)$ note is a particular difficulty with the empirical implementation of the

\footnotetext{
${ }^{2}$ Jones and Pewsey $(2009,761-762)$ refer to the particular functional forms employed in our analysis as the sinharcsinh class of transformations.

${ }^{3}$ The European sovereign debt crisis under which the European Central Bank provided loans of more than one trillion euro to maintain money flows between European banks, demonstrates the devastating effect that extreme variations in the availability of cash can have on commercial and industrial activities.
} 
Pearson Type IV probability density. Here we show that the moments for the Type IV probability density are in general undefined (that is, non-convergent). Moreover, we also note how the non-algebraic nature of the Type IV normalising constant compromises parameter estimation based on the maximum likelihood procedure (Heinrich 2004, 5). Given this, parameter estimation is implemented using the " $\chi^{2}$ minimum method" based on the Cramér-von Mises goodness of fit statistic as summarised by Cramér (1946, 426-427). ${ }^{4}$ Section 5 illustrates parameter estimation for the Type IV probability density based on the $\chi^{2}$ minimum method and the quarterly cash and cash equivalent balances of 100 randomly selected U.S. corporations covering the period from 2006 until 2017. Chi-square goodness of fit test statistics based on these parameter estimates demonstrate that that the Type IV probability density is strongly compatible with the quarterly cash and cash equivalent balance data of all but four of the 100 corporations on which our empirical analysis is based. In contrast, around sixty per cent of the 100 corporations return statistically significant Jarque and Bera (1980) test statistics - thereby signifying that it is highly unlikely the quarterly cash and cash equivalent balance data are compatible with the random walk assumptions on which the Miller and Orr (1966) and many subsequent cash management models, have been based. ${ }^{5}$ Section 6 provides our summary conclusions.

\footnotetext{
${ }^{4}$ Mood, Graybill and Boes $(1974,286-287)$ refer to this procedure as the "minimum distance method". Avni (1976) and Berkson (1980) develop its major mathematical properties and in particular, compare its efficiency with maximum likelihood parameter estimation procedures. Guo et al. (2016) and Chen et al. (2016) give a detailed exposition of how the $\chi^{2}$ minimum method may be empirically implemented.

${ }^{5}$ The Jarque and Bera $(1980,256)$ test is based on the null hypothesis of Gaussian distributed data against the alternative hypothesis that the data are generated by one of the Pearson family of probability densities. This means the Jarque-Bera test will have maximum asymptotic power in discriminating between the random walk (that is, Gaussian) distributional assumptions on which the Miller and Orr (1966) cash management model is based (Karlin and Taylor 1981, 342) and the Pearson Type IV probability density on which the cash management model developed here is based.
} 


\section{Literature Review}

The literature describes a multitude of potential approaches to the modelling of optimal cash balances held by firms; namely, deterministic models (including linear and dynamic programming techniques), stochastic models, mixed deterministic-stochastic models, simulation models and evolutionary models, to name some of the more important approaches which appear in the literature (da Costa Moraes et al. 2015). This literature review, however, focuses on stochastic cash management models only and more particularly, on continuoustime variants of these models.

Undoubtedly the seminal work by Miller and Orr (1966) is the key paper in the area of stochastic cash balance modelling (Karlin and Taylor 1981, 211-212). These authors are the first to develop the hitherto deterministic cash models into a truly stochastic model that determines optimal cash management policies for the firm. Their approach imposes upper and lower control limits on the cash balance which are determined by minimising the expected annual cost of maintaining the firm's cash balances. Cash balances are assumed to evolve in terms of a pure random walk. Here, however, Miller and Orr $(1966,430)$ acknowledge that modelling cash flow behaviour in terms of a pure random walk is seemingly at odds with empirical observation in the sense that management invariably has at least partial control over the cash balances maintained by the firm. Given this, the Miller and Orr (1966) model has subsequently been refined and expanded to include features such as the admission of negative cash flows, variable and fixed transaction costs and, importantly, continuous-time probability distributions. Amongst the papers that have contributed to these improvements are Eppen and Fama (1969), Daellenbach (1971), Hinderer and Waldmann (2001), Gormley and Meade (2007) and Yao, Chen, and Lu (2006) and Wang et al. (2018). For a more detailed overview of these and other papers, one may refer to Mallaris (1989) and, more recently, da Costa Moraes et al. (2015). 
Vial (1970) and Constantinides (1976) are early publications that show the importance of the Wiener process in the modelling of cash balances. Numerous authors have followed in their footsteps, and tried and tested a variety of stochastic specifications derived from the general Itô specification. Premachandra (2004), for example, assumes that cash balances are governed by a diffusion process with upper and lower control limits; he then relaxes the strict random walk assumptions behind the Miller and Orr (1966) model by allowing the time it takes for cash to be withdrawn or deposited into the firm's bank account to be described by an exponential random variable with given mean and variance. Baccarin (2009) describes fluctuating cash balances as a homogeneous diffusion process in a multidimensional $\mathfrak{R}^{n}$ Wiener probability space. Frenkel and Jovanovic (1978) and Smith (1986) examine the suitability of the Uhlenbeck and Ornstein (1930) diffusion process for the modelling of cash balance processes. Wang et al. (2018) invoke the neoclassical tradition of assuming economic agents (that is, firm managers) maximise the utility from holding cash (Patinkin 1965) but where the cash balance is constrained to evolve in terms of a "safe area" which insures that specific levels of liquidity are maintained. The Wang et al. (2018) analysis assumes in particular that cash earns a known risk free rate of return whilst the risky assets in which the firm invests have values which evolve in terms of a Geometric Brownian Motion. Basing their analysis on Merton (1969) they then determine the "safe area" liquidity strategy which maximises the expected utility from holding cash. Based on the expectation that the demand for cash grows if the size of the organisation expands, Higson et al. (2010) propose a (non-stationary) square root process for the modelling cash balances - an approach that results in optimal cash management policies that are fundamentally different to those obtained under the Miller and Orr (1966) specification. Other stochastic processes have also been advanced as, for example, the compound Poisson process implemented by Tapiero and Zuckerman (1980). 
We now follow Miller and Orr (1966) in developing a model in which firms implement cash management policies that minimise the likelihood of their productive processes being disrupted by extreme variations in their cash balances. However, we avoid the pure random walk assumptions on which the Miller and Orr (1966) cash management model is based by using the hyperbolic cash flows and probabilities which lead to the Pearson Type IV probability density. This will mean that firm cash flows are comprised of deterministic fixed and variable components and a stochastic element that grows in volatility as the cash flow itself grows in absolute magnitude (Black 1995, Cox, Ingersoll and Ross, 1985).

\section{Hyperbolic Cash Balance Model}

Let $x(t)$ be the balance on a firm's bank account (that is, its cash balance) at time $t$. It then follows $d x(t)=x(t+d t)-x(t)$ will be the cash flow that accrues to the firm's bank account over the infinitesimal period from $t$ until $(t+d t)$. Moreover, one can use Bartlett's general polynomial representation of a diffusion process (Cox and Miller 1965, 218) in conjunction with the hyperbolic transformations of Jones and Pewsey $(2009,761-762)$ to provide a general description of the infinitesimal cash flow earned by a firm using the following stochastic differential equation: ${ }^{6}$

$$
d x(t)=\{\alpha+\beta x(t)-D(t)\} d t+\sqrt{1+\left\{k_{0}+\frac{k_{2} x(t)}{\sqrt{2}}\right\}^{2}} d q(t)
$$

${ }^{6}$ Bartlett $(1955,83)$ considers the class of stochastic differential equations of the following general form:

$$
d x(t)=\beta(x) d t+\sqrt{\alpha(x)} d q(t)
$$

where $\beta(x)$ and $\alpha(x)$ are analytic functions and $d q(t)$ is a white noise process with unit variance parameter. Bartlett (1955) then applies Taylor expansions to $\beta(x)$ and $\alpha(x)$ which can be truncated at any given order of approximation. Our analysis is based on a linear approximation for $\beta(x)$ and a quadratic approximation for $\alpha(x)$. However, the quadratic approximation for $\alpha(x)$ is stated in such a way as to permit the use of the inverse sinh transformations of Jones and Pewsey (2009) to simplify the Fokker-Planck equation and thereby facilitate the determination of the probability density associated with the truncated interpretation of the stochastic differential equation. The inverse sinh transformation applied in our analysis is in fact a parsimonious interpretation of the Lamperti Transform of Møller, and Madsen (2010,11). 
Here $\alpha, \beta, k_{0}$ and $k_{2}$ are parameters and $d q(t)$ is a white noise process with unit variance parameter. Moreover, $D(t)$ represents infinitesimal cash withdrawals and injections into the firm's bank account (borrowing, the liquidation of assets held by the firm, the purchase of available for sale securities, etc.) and is configured so as to minimise the likelihood of the firm's productive processes being disrupted by extreme variations in its cash balances over time. ${ }^{7}$ The magnitude of time series variations in the firm's cash balances is modelled by the integral sum of the discounted squared cash balances held by the firm, in which case $D(t)$ is determined so as to satisfy the following criterion:

$$
\underset{D}{\operatorname{Min}} G(x, t)=E\left\{\int_{t}^{\infty} e^{-\rho s}[x(s)-D(s)]^{2} d s\right\}
$$

and where $\rho$ is the interest (or discount) rate applied to future cash balances and $E(\cdot)$ is the expectation operator. Here, one can use the differential equation (1) describing the evolution of the firm's infinitesimal cash flows in conjunction with equation (2) to specify the Hamilton-Jacobi-Bellman fundamental equation of optimality; namely (Arnold 1974, 212213):

$$
\operatorname{Min}_{D} \phi(D)=0=e^{-\rho t}(x-D)^{2}+(\alpha+\beta x-D) \frac{\partial G}{\partial x}+\frac{1}{2}\left(1+\left\{k_{0}+\frac{k_{2} x}{\sqrt{2}}\right\}^{2}\right) \frac{\partial^{2} G}{\partial x^{2}}+\frac{\partial G}{\partial t}
$$

Differentiating through the above expression will then lead to the following inter-temporal envelope condition: ${ }^{8}$

\footnotetext{
${ }^{7}$ See Keynes (1936, 194-199) for a detailed summary of the factors which influence the determination of $D$. These include what Keynes broadly defined as the transactions, precautionary and the speculative demand for money.

${ }^{8}$ The envelope condition is determined from the requirement:
}

$$
\phi^{\prime}(D)=-2 e^{-\rho t}(x-D)-\frac{\partial G}{\partial x}=0
$$




$$
D=x+\frac{1}{2} e^{\rho t} \frac{\partial G}{\partial x}
$$

One can then substitute the envelope condition back into equation (3) and thereby show that the optimised interpretation of the Hamilton-Jacobi-Bellman equation is given by:

$$
0=-\frac{1}{4} e^{\rho t}\left(\frac{\partial G}{\partial x}\right)^{2}+(\alpha+(\beta-1) x) \frac{\partial G}{\partial x}+\frac{1}{2}\left(1+\left\{k_{0}+\frac{k_{2} x}{\sqrt{2}}\right\}^{2}\right) \frac{\partial^{2} G}{\partial x^{2}}+\frac{\partial G}{\partial t}
$$

Moreover, one can simplify the above expression by letting $G(x, t)=e^{-\rho t} J(x)$ in which case it follows $\frac{\partial G}{\partial x}=e^{-\rho t} J^{\prime}(x)$ and $\frac{\partial^{2} G}{\partial x^{2}}=e^{-\rho t} J^{\prime \prime}(x)$. Substitution will then show that the optimised Hamilton-Jacobi-Bellman equation assumes the following canonical form:

$$
0=-\frac{1}{4}\left(J^{\prime}(x)\right)^{2}+(\alpha+(\beta-1) x) J^{\prime}(x)+\frac{1}{2}\left(1+\left\{k_{0}+\frac{k_{2} x}{\sqrt{2}}\right\}^{2}\right) J^{\prime \prime}(x)-\rho J(x)
$$

To solve the above differential equation we take as a trial solution (Merton 1969, 250):

$$
J(x)=c+(a+b x)^{2}
$$

where $a, b$ and $c$ are chosen so as to insure that (7) satisfies the differential equation (6) for the given (that is, known) values of $k_{0}, k_{2}, \alpha$ and $\beta$ as given in equation (1). Substitution will then show that $\rho=\frac{b^{2}}{c}$ and: 


$$
\left.\begin{array}{l}
k_{0}^{2}=a\left(a+\frac{a}{c}-\frac{2 \alpha}{b}\right) \\
\frac{k_{0} k_{2}}{\sqrt{2}}=a b+\frac{a b}{c}+\frac{a(1-\beta)}{b}-\alpha \\
\frac{1}{2} k_{2}^{2}=b^{2}+\frac{b^{2}}{c}+2(1-\beta)
\end{array}\right\}
$$

Furthermore, substituting $\frac{\partial G}{\partial x}=e^{-\rho t} J^{\prime}(x)=2 b e^{-\rho t}(a+b x)$ into the envelope condition (4) will then mean that the optimal control for cash withdrawals and injections will take the form:

$$
D=x+b(a+b x)
$$

Hence, using this result in conjunction with equation (1) will then show that the balance on the firm's bank account, $x$, will evolve in terms of the following differential equation:

$$
d x(t)=(A+B x) d t+\sqrt{1+\left\{k_{0}+\frac{k_{2} x}{\sqrt{2}}\right\}^{2}} d q(t)
$$

where $A=(\alpha-b a)$ and $B=\left(\beta-1-b^{2}\right)$. Equipped with these results, we now determine the distributional properties of the firm's cash balances by invoking the Fokker-Planck equation based on the differential equation (10).

\section{Distributional Properties and Parameter Estimation}

We begin our analysis in this section by making the substitution (Jones and Pewsey 2009):

$$
z=\frac{\sqrt{2}}{k_{2}} \sinh ^{-1}\left(k_{0}+\frac{k_{2}}{\sqrt{2}} x\right)
$$

into the differential equation (10). Now, here it will be noted: 


$$
\frac{\partial z}{\partial x}=\frac{1}{\sqrt{1+\left\{k_{0}+\frac{k_{2} x}{\sqrt{2}}\right\}^{2}}} \text { and } \frac{\partial^{2} z}{\partial x^{2}}=\frac{-\frac{k_{2}}{\sqrt{2}}\left(k_{0}+\frac{k_{2} x}{\sqrt{2}}\right)}{\left\{1+\left(k_{0}+\frac{k_{2} x}{\sqrt{2}}\right)^{2}\right\}^{3 / 2}}
$$

Using these results in conjunction with Itô's formula will then show:

$$
\begin{gathered}
d z=\frac{\partial z}{\partial x} d x+\frac{1}{2} \frac{\partial^{2} z}{\partial x^{2}}(d x)^{2}= \\
\frac{(A+B x) d t+\sqrt{1+\left(k_{0}+\frac{k_{2} x}{\sqrt{2}}\right)^{2}} d q}{\sqrt{1+\left(k_{0}+\frac{k_{2} x}{\sqrt{2}}\right)^{2}}}-\frac{1}{2} \frac{\left[1+\left\{k_{0}+\frac{k_{2} x(t)}{\sqrt{2}}\right\}^{2}\right]\left[\frac{k_{2} x}{\sqrt{2}}+k_{0}\right] \frac{k_{2}}{\sqrt{2}}}{\left[1+\left\{k_{0}+\frac{k_{2} x(t)}{\sqrt{2}}\right\}^{2}\right]^{3 / 2}} d t
\end{gathered}
$$

or equivalently:

$$
d z=\frac{\left\{A+B x(t)-\frac{k_{2}}{2 \sqrt{2}}\left[\frac{k_{2} x(t)}{\sqrt{2}}+k_{0}\right]\right\} d t}{\sqrt{1+\left\{k_{0}+\frac{k_{2} x(t)}{\sqrt{2}}\right\}^{2}}}+d q
$$

Moreover, simple algebraic manipulation will demonstrate that the above expression is equivalent to:

$$
d z=\frac{\left\{\left[\frac{\sqrt{2} B}{k_{2}}-\frac{k_{2}}{2 \sqrt{2}}\right]\left[\frac{k_{2} x(t)}{\sqrt{2}}+k_{0}\right]+\left[A-\frac{\sqrt{2} B k_{0}}{k_{2}}\right]\right\} d t}{\sqrt{1+\left\{k_{0}+\frac{k_{2} x(t)}{\sqrt{2}}\right\}^{2}}}+d q
$$

Now, here it will be recalled from equation (11) that $\frac{k_{2}}{\sqrt{2}} x(t)+k_{0}=\sinh \left(\frac{k_{2} z}{\sqrt{2}}\right)$ in which case we have: 


$$
\sqrt{1+\left\{k_{0}+\frac{k_{2} x(t)}{\sqrt{2}}\right\}^{2}}=\sqrt{1+\sinh ^{2}\left(\frac{k_{2} z}{\sqrt{2}}\right)}=\cosh \left(\frac{k_{2} z}{\sqrt{2}}\right)
$$

One can then substitute equation (11) and equation (14) into equation (13) and thereby show that the transformed bank balance will evolve in accordance with the following differential equation:

$$
d z=\left\{\left(\frac{\sqrt{2} B}{k_{2}}-\frac{k_{2}}{2 \sqrt{2}}\right) \tanh \left(\frac{k_{2} z}{\sqrt{2}}\right)+\left(A-\frac{\sqrt{2} B k_{0}}{k_{2}}\right) \operatorname{sech}\left(\frac{k_{2} z}{\sqrt{2}}\right)\right\} d t+d q
$$

It then follows that infinitesimal increments in the transformed bank balance will have a mean (per unit time) of:

$$
\frac{E[d z(t)]}{d t}=\left(\frac{\sqrt{2} B}{k_{2}}-\frac{k_{2}}{2 \sqrt{2}}\right) \tanh \left(\frac{k_{2} z}{\sqrt{2}}\right)+\left(A-\frac{\sqrt{2} B k_{0}}{k_{2}}\right) \sec h\left(\frac{k_{2} z}{\sqrt{2}}\right)
$$

whilst its variance (again on a per unit time basis) has been stabilised to:

$$
\frac{\operatorname{Var}[d z(t)]}{d t}=1
$$

a result which streamlines much of our subsequent analysis. Moreover, when $B=\frac{k_{2}^{2}}{4}$ and $A=\frac{k_{0} k_{2}}{2 \sqrt{2}}$ the firm's transformed bank balance, $z$, will evolve in terms of a pure white noise process. Thus, integrating through equation (15) using the given parameter values will mean that the simple canonical interpretation of the hyperbolic cash balance model given here implies (Cox and Miller 1965, 209-210):

$$
\frac{\sqrt{2}\left[\sinh ^{-1}\left\{k_{0}+\frac{k_{2}}{\sqrt{2}} x(t)\right\}-\sinh ^{-1}\left\{k_{0}+\frac{k_{2}}{\sqrt{2}} x(0)\right\}\right]}{k_{2} \sqrt{t}}
$$


will evolve in terms of the standard normal probability density.

For the more general case, the Fokker-Planck (that is, forward Kolmogorov) equation shows that the conditional probability density for the transformed bank balance, $g(z, t)$, is related to the mean and variance of infinitesimal increments in the transformed bank balance through the following result (Cox and Miller 1965, 213-215):

$$
\frac{\partial g(z, t)}{\partial t}=\frac{1}{2} \frac{\partial^{2}}{\partial z^{2}}\left\{\frac{\operatorname{Var}[d z(t)]}{d t} g(z, t)\right\}-\frac{\partial}{\partial z}\left\{\frac{E[d z(t)]}{d t} g(z, t)\right\}
$$

Substituting equation (16a) for the infinitesimal mean and equation (16b) for the infinitesimal variance of the transformed bank balance into equation (18) will then show that the FokkerPlanck equation becomes:

$$
\frac{\partial g(z, t)}{\partial t}=\frac{1}{2} \frac{\partial^{2} g(z, t)}{\partial z^{2}}-\frac{\partial}{\partial z}\left\{\left[\left(\frac{\sqrt{2} B}{k_{2}}-\frac{k_{2}}{2 \sqrt{2}}\right) \tanh \left(\frac{k_{2} z}{\sqrt{2}}\right)+\left(A-\frac{\sqrt{2} B k_{0}}{k_{2}}\right) \sec h\left(\frac{k_{2} z}{\sqrt{2}}\right)\right] g(z, t)\right\}
$$

Now, let us suppose that the transformed bank balance has an unconditional probability density which is independent of the bank account's opening balance - that is, is independent of the initial condition, $x(0)$. It then follows (Karlin and Taylor 1981, 220-222):

$$
\operatorname{Limit}_{t \rightarrow \infty} \frac{\partial g(z, t)}{\partial t}=0
$$

in which case the Fokker-Planck equation reduces to the following ordinary differential equation:

$$
\frac{1}{2} \frac{d^{2} g(z)}{d z^{2}}=\frac{d}{d z}\left\{\left[\left(\frac{\sqrt{2} B}{k_{2}}-\frac{k_{2}}{2 \sqrt{2}}\right) \tanh \left(\frac{k_{2} z}{\sqrt{2}}\right)+\left(A-\frac{\sqrt{2} B k_{0}}{k_{2}}\right) \operatorname{sech}\left(\frac{k_{2} z}{\sqrt{2}}\right)\right] g(z)\right\}
$$


Moreover, integrating through this equation will then show:

$$
\frac{d g(z)}{d z}+\left\{\left(\frac{k_{2}}{\sqrt{2}}-\frac{2 \sqrt{2} B}{k_{2}}\right) \tanh \left(\frac{k_{2} z}{\sqrt{2}}\right)+2\left(\frac{\sqrt{2} B k_{0}}{k_{2}}-A\right) \operatorname{sech}\left(\frac{k_{2} z}{\sqrt{2}}\right)\right\} g(z)=c_{1}
$$

where $c_{1}$ is a constant of integration. One can then multiply through this latter equation by the integrating factor (Boyce and DiPrima 2005, 36):

$$
\left\{\cosh \left(\frac{k_{2} z}{\sqrt{2}}\right)\right\}^{\left(1-\frac{4 B}{k_{2}^{2}}\right)} \exp \left\{\frac{2 \sqrt{2}}{k_{2}}\left(\frac{\sqrt{2} B k_{0}}{k_{2}}-A\right) \tan ^{-1}\left[\sinh \left(\frac{k_{2} z}{\sqrt{2}}\right)\right]\right\}
$$

and thereby show that the Fokker-Planck equation has the following equivalent representation:

$$
\begin{aligned}
\frac{d}{d z}\left\langle\left\{\cosh \left(\frac{k_{2} z}{\sqrt{2}}\right)\right\}^{\left(1-\frac{4 B}{k_{2}^{2}}\right)} \exp \left\{\frac{2 \sqrt{2}}{k_{2}}\left(\frac{\sqrt{2} B k_{0}}{k_{2}}-A\right) \tan ^{-1}\left[\sinh \left(\frac{k_{2} z}{\sqrt{2}}\right)\right]\right\} g(z)\right\rangle= \\
c_{1}\left\{\cosh \left(\frac{k_{2} z}{\sqrt{2}}\right)\right\}^{\left(1-\frac{4 B}{k_{2}^{2}}\right)} \exp \left\{\frac{2 \sqrt{2}}{k_{2}}\left(\frac{\sqrt{2} B k_{0}}{k_{2}}-A\right) \tan ^{-1}\left[\sinh \left(\frac{k_{2} z}{\sqrt{2}}\right)\right]\right\}
\end{aligned}
$$

Integrating across the above equation and setting $c_{1}=0^{9}$ will then show that the stationary (that is, unconditional) probability density for the transformed bank balance will take the form:

$$
g(z)=c_{2}\left\{\cosh \left(\frac{k_{2} z}{\sqrt{2}}\right)\right\}^{\left(\frac{4 B}{k_{2}^{2}}-1\right)} \exp \left\{\frac{2 \sqrt{2}}{k_{2}}\left(A-\frac{\sqrt{2} B k_{0}}{k_{2}}\right) \tan ^{-1}\left[\sinh \left(\frac{k_{2} z}{\sqrt{2}}\right)\right]\right\}
$$

\footnotetext{
9 Without this condition the differential equation will lead to a non-convergent distribution function and a stationary probability density will not exist (Karlin and Taylor 1981, 221).
} 
or, upon substitution:

$g(x)=c_{2} \frac{\exp \left\{\frac{2 \sqrt{2}}{k_{2}}\left(A-\frac{\sqrt{2} B k_{0}}{k_{2}}\right) \tan ^{-1}\left(\frac{k_{2} x}{\sqrt{2}}+k_{0}\right)\right\}}{\left\{1+\left(\frac{k_{2} x}{\sqrt{2}}+k_{0}\right)^{2}\right\}^{\frac{1}{2}\left(1-\frac{4 B}{k_{2}^{2}}\right)}}=c_{2} \frac{\exp \left\{\frac{2 \sqrt{2}}{k_{2}}\left(A-\frac{\sqrt{2} B k_{0}}{k_{2}}\right) \tan ^{-1}\left(\frac{x+\frac{\sqrt{2} k_{0}}{k_{2}}}{\frac{\sqrt{2}}{k_{2}}}\right)\right\}}{\left\{1+\left(\frac{x+\frac{\sqrt{2} k_{0}}{k_{2}}}{\frac{\sqrt{2}}{k_{2}}}\right)^{2}\right\}^{\frac{1}{2}\left(1-\frac{4 B}{k_{2}^{2}}\right)}}$

where, as previously, $A=(\alpha-b a), B=-\left(b^{2}+1-\beta\right)<0$ and $c_{2}$ is a second constant of integration determined so as to ensure a unit probability mass. An exact parametric expression for the normalising constant is given by (Heinrich 2004, 5):

$$
c_{2}=\frac{k_{2} \Gamma\left\{\frac{1}{2}\left(1-\frac{4 B}{k_{2}^{2}}\right)\right\}}{\sqrt{2 \pi} \Gamma\left(-\frac{2 B}{k_{2}^{2}}\right)}\left|\frac{\Gamma\left\{\frac{1}{2}\left(1-\frac{4 B}{k_{2}^{2}}\right)-\frac{i \sqrt{2}}{k_{2}}\left(A-\frac{\sqrt{2} B k_{0}}{k_{2}}\right)\right\}}{\Gamma\left\{\frac{1}{2}\left(1-\frac{4 B}{k_{2}^{2}}\right)\right\}}\right|^{2}
$$

where $\Gamma(\cdot)$ is the gamma function, $i=\sqrt{-1}$ is the pure imaginary number and $|\cdot|$ denotes the complex norm. Moreover, Heinrich $(2004,5)$ shows how the normalising constant can be evaluated in terms of the hypergeometric function (Abramowitz and Stegun 1964, 556) although "convergence is slow" and "CPU-intensive even when only moderate precision is required." These factors combined with the non-algebraic nature of the normalising constant will mean that it is difficult to obtain reliable estimates of parameters using the Maximum 
Likelihood procedure (Kendall and Stuart 1977, 163; Nagahara 1999; Jones and Pewsey 2009, 768).

A commonly employed alternative, however, involves estimating parameters using the (Generalised) Method of Moments (Hall 2005). For this one must apply logarithmic differentiation to the density function, $g(x)$, in which case it follows:

$$
\frac{g^{\prime}(x)}{g(x)}=\frac{2\left(A-\frac{\sqrt{2} B k_{0}}{k_{2}}\right)}{\left\{1+\left(\frac{k_{2} x}{\sqrt{2}}+k_{0}\right)^{2}\right\}}-\frac{\left(\frac{k_{2}}{\sqrt{2}}-\frac{2 \sqrt{2} B}{k_{2}}\right)\left(\frac{k_{2} x}{\sqrt{2}}+k_{0}\right)}{\left\{1+\left(\frac{k_{2} x}{\sqrt{2}}+k_{0}\right)^{2}\right\}}
$$

Moreover, multiplying through the above equation by $\left(\frac{k_{2} x}{\sqrt{2}}+k_{0}\right)^{j}$ for integral values of $j$ and integrating over the real line, will show:

$$
\begin{aligned}
& \int_{-\infty}^{\infty}\left\{1+\left(\frac{k_{2} x}{\sqrt{2}}+k_{0}\right)^{2}\right\}\left(\frac{k_{2} x}{\sqrt{2}}+k_{0}\right)^{j} g^{\prime}(x) d x= \\
& \qquad \int_{-\infty}^{\infty}\left\{2\left(A-\frac{\sqrt{2} B k_{0}}{k_{2}}\right)-\frac{k_{2}}{\sqrt{2}}\left(1-\frac{4 B}{k_{2}^{2}}\right)\left(\frac{k_{2} x}{\sqrt{2}}+k_{0}\right)\right\}\left(\frac{k_{2} x}{\sqrt{2}}+k_{0}\right)^{j} g(x) d x
\end{aligned}
$$

On applying integration by parts to the left hand side of the above expression we end up with:

$$
\begin{aligned}
-\int_{-\infty}^{\infty}\left\{\frac{j k_{2}}{\sqrt{2}}\left(\frac{k_{2} x}{\sqrt{2}}+k_{0}\right)^{j-1}+\frac{(j+2) k_{2}}{\sqrt{2}}\left(\frac{k_{2} x}{\sqrt{2}}+k_{0}\right)^{j+1}\right\} g(x) d x= \\
\\
\qquad \int_{-\infty}^{\infty}\left\{2\left(A-\frac{\sqrt{2} B k_{0}}{k_{2}}\right)\left(\frac{k_{2} x}{\sqrt{2}}+k_{0}\right)^{j}-\frac{k_{2}}{\sqrt{2}}\left(1-\frac{4 B}{k_{2}^{2}}\right)\left(\frac{k_{2} x}{\sqrt{2}}+k_{0}\right)^{j+1}\right\} g(x) d x
\end{aligned}
$$

or equivalently: 


$$
j E\left\{\left(\frac{k_{2} x}{\sqrt{2}}+k_{0}\right)^{j-1}\right\}+\left(\frac{2 \sqrt{2} A}{k_{2}}-\frac{4 B k_{0}}{k_{2}^{2}}\right) E\left\{\left(\frac{k_{2} x}{\sqrt{2}}+k_{0}\right)^{j}\right\}+\left\{(j+1)+\frac{4 B}{k_{2}^{2}}\right\} E\left\{\left(\frac{k_{2} x}{\sqrt{2}}+k_{0}\right)^{j+1}\right\}=0
$$

and where, as previously, $E(\cdot)$ is the expectation operator. Thus, setting $j=0$ in this formula will show:

$$
E\left(\frac{k_{2} x}{\sqrt{2}}+k_{0}\right)=\frac{-\left(\frac{2 \sqrt{2} A}{k_{2}}-\frac{4 B k_{0}}{k_{2}^{2}}\right)}{\left(1+\frac{4 B}{k_{2}^{2}}\right)}
$$

Furthermore, setting $j=1$ and substituting equation (28) into equation (29) will also show:

$$
E\left\{\left(\frac{k_{2} x}{\sqrt{2}}+k_{0}\right)^{2}\right\}=\frac{\left(\frac{2 \sqrt{2} A}{k_{2}}-\frac{4 B k_{0}}{k_{2}^{2}}\right)^{2}}{\left(1+\frac{4 B}{k_{2}^{2}}\right)\left(2+\frac{4 B}{k_{2}^{2}}\right)}-\frac{1}{\left(2+\frac{4 B}{k_{2}^{2}}\right)}
$$

Similar calculations will show that the third $(j=2)$ and fourth $(j=3)$ moments are, respectively:

$$
E\left\{\left(\frac{k_{2} x}{\sqrt{2}}+k_{0}\right)^{3}\right\}=\frac{2\left(\frac{2 \sqrt{2} A}{k_{2}}-\frac{4 B k_{0}}{k_{2}^{2}}\right)}{\left(1+\frac{4 B}{k_{2}^{2}}\right)\left(3+\frac{4 B}{k_{2}^{2}}\right)}+\frac{\left(\frac{2 \sqrt{2} A}{k_{2}}-\frac{4 B k_{0}}{k_{2}^{2}}\right)}{\left(2+\frac{4 B}{k_{2}^{2}}\right)\left(3+\frac{4 B}{k_{2}^{2}}\right)}-\frac{\left(\frac{2 \sqrt{2} A}{k_{2}}-\frac{4 B k_{0}}{k_{2}^{2}}\right)^{3}}{\left(1+\frac{4 B}{k_{2}^{2}}\right)\left(2+\frac{4 B}{k_{2}^{2}}\right)\left(3+\frac{4 B}{k_{2}^{2}}\right)}
$$

and: 


$$
\begin{gathered}
E\left\{\left(\frac{k_{2} x}{\sqrt{2}}+k_{0}\right)^{4}\right\}=\frac{\left(\frac{2 \sqrt{2} A}{k_{2}}-\frac{4 B k_{0}}{k_{2}^{2}}\right)^{4}}{\left(1+\frac{4 B}{k_{2}^{2}}\right)\left(2+\frac{4 B}{k_{2}^{2}}\right)\left(3+\frac{4 B}{k_{2}^{2}}\right)\left(4+\frac{4 B}{k_{2}^{2}}\right)}+\frac{3}{\left(2+\frac{4 B}{k_{2}^{2}}\right)\left(4+\frac{4 B}{k_{2}^{2}}\right)}- \\
\frac{3\left(\frac{2 \sqrt{2} A}{k_{2}}-\frac{4 B k_{0}}{k_{2}^{2}}\right)^{2}}{\left(1+\frac{4 B}{k_{2}^{2}}\right)\left(2+\frac{4 B}{k_{2}^{2}}\right)\left(4+\frac{4 B}{k_{2}^{2}}\right)}-\frac{2\left(\frac{2 \sqrt{2} A}{k_{2}}-\frac{4 B k_{0}}{k_{2}^{2}}\right)^{2}}{\left(1+\frac{4 B}{k_{2}^{2}}\right)\left(3+\frac{4 B}{k_{2}^{2}}\right)\left(4+\frac{4 B}{k_{2}^{2}}\right)}-\frac{\left(\frac{2 \sqrt{2} A}{k_{2}}-\frac{4 B k_{0}}{k_{2}^{2}}\right)^{2}}{\left(2+\frac{4 B}{k_{2}^{2}}\right)\left(3+\frac{4 B}{k_{2}^{2}}\right)\left(4+\frac{4 B}{k_{2}^{2}}\right)}
\end{gathered}
$$

Expressions for the central moments are easily determined from the above results, as for example, the mean of the firm's cash balance which is given by:

$$
E(x)=-\frac{\frac{4 A}{k_{2}^{2}}+\frac{\sqrt{2} k_{0}}{k_{2}}}{1+\frac{4 B}{k_{2}^{2}}}
$$

Similarly, the variance of the firm's cash balance will be given by:

$$
\operatorname{Var}(x)=\frac{2}{k_{2}^{2}}\left[E\left\{\left(\frac{k_{2} x}{\sqrt{2}}+k_{0}\right)^{2}\right\}-\left\{E\left(\frac{k_{2} x}{\sqrt{2}}+k_{0}\right)\right\}^{2}\right]
$$

or, upon substitution:

$$
\operatorname{Var}(x)=\frac{2}{k_{2}^{2}}\left\{\frac{\left(\frac{2 \sqrt{2} A}{k_{2}}-\frac{4 B k_{0}}{k_{2}^{2}}\right)^{2}}{\left(1+\frac{4 B}{k_{2}^{2}}\right)\left(2+\frac{4 B}{k_{2}^{2}}\right)}-\frac{1}{\left(2+\frac{4 B}{k_{2}^{2}}\right)}-\frac{\left(\frac{4 B k_{0}}{k_{2}^{2}}-\frac{2 \sqrt{2} A}{k_{2}}\right)^{2}}{\left(1+\frac{4 B}{k_{2}^{2}}\right)^{2}}\right\}
$$

where, as previously, $\operatorname{Var}(\cdot)$ is the variance operator. Similar calculations may be used to determine the third, fourth and all higher central moments for the balance on the firm's bank 
account. More important, however, is the observation that the moments will in general be undefined (as, for example, with the variance when $\frac{4 B}{k_{2}^{2}}=-1$ or $\frac{4 B}{k_{2}^{2}}=-2$ ). ${ }^{10}$ The potential absence of convergent moments will mean parameter estimation based on the (Generalised) Method of Moments may be both inconsistent and inefficient. Hence, given the limitations of the Maximum Likelihood and (Generalised) Method of Moments techniques in the present context, parameter estimation is conducted using the " $\chi^{2}$ minimum method" based on the Cramér-von Mises goodness of fit statistic as summarised by Cramér (1946, 426-427).

\section{Data and Empirical Analysis}

Our data are comprised of the quarterly cash and cash equivalent balances (Compustat item 74) for 100 randomly selected North American corporations covering the period from 2006 until 2017 as summarised in the first three columns of Table $1 .^{11}$ Thus, for Canam Group Inc. our analysis is based on $N=41$ quarterly cash and cash equivalent balance observations covering the period from 31 March, 2006 until 31 March, 2017. To calculate the Cramér-von Mises goodness of fit statistic one must first order these cash balance figures from the lowest cash balance up to the highest cash balance. For Canam Group Inc., we then have $w_{1}=\$ 2.498$ to be the lowest quarterly cash balance, $w_{2}=\$ 3.641$ to be the second lowest cash balance, $w_{3}=\$ 4.690$ to be the third lowest cash balance and so on, right up to the largest cash balance figure which is $w_{41}=\$ 67.393$. The Cramér-von Mises goodness of fit statistic, $T_{3}$, is then determined from the following formula (Kendall and Stuart 1979, 476):

$$
T_{3}=\frac{1}{12 N}+\sum_{p=1}^{N}\left[\int_{-1}^{z_{p}} g(z) d z-\frac{2 p-1}{2 N}\right]^{2}
$$

\footnotetext{
${ }^{10}$ See Heinrich $(2004,4)$ for a more detailed discussion of this issue.

${ }^{11}$ With a few exceptions, 2006 is the earliest date from which quarterly cash and cash equivalent balances data are available on the Compustat file.
} 
Here $z_{p}=\frac{-2}{\pi} \tan ^{-1}\left(\frac{k_{2} x_{p}}{\sqrt{2}}+k_{0}\right)$ and $x_{p}=w_{p}-\frac{1}{N} \sum_{j=1}^{N} w_{j}$ is the abnormal component of the $p^{\text {th }}$ ordered cash balance comprising the Canam Group Inc. sample data. Moreover, $\int_{-1}^{z_{p}} g(z) d z$ is the accumulated area under the probability density (25) below the $p^{\text {th }}$ ordered cash balance - which was evaluated using the 15 point Gauss-Legendre quadrature formula (Carnahan, Luther and Wilkes 1969, 101-105). The composite parameters which define the probability density (25); namely, $\xi_{1} \equiv \frac{k_{2}}{k_{0}}, \quad \xi_{2} \equiv \frac{2 \sqrt{2}}{k_{2}}\left(A-\frac{\sqrt{2} B k_{0}}{k_{2}}\right) \quad$ and $\quad \xi_{3} \equiv \frac{1}{2}\left(1-\frac{4 B}{k_{2}^{2}}\right)$ were then estimated so as to minimise the Cramér-von Mises goodness of fit statistic (35). ${ }^{12}$ Thus, in the case of Canam Group Inc., Table 1 shows that the $N=41$ quarterly cash and cash equivalent balance observations covering the period from 31 March, 2007 until 31 March, 2017 lead to a minimised Cramér-von Mises goodness of fit statistic of $T_{3}=0.0225$ as summarised in the seventh column of Table 1. Moreover, the minimised Cramér-von Mises

\section{INSERT TABLE ONE ABOUT HERE}

goodness of fit statistic is based on the estimated parameter values $\xi_{1}=0.1132, \xi_{2}=-4.3424$ and $\xi_{3}=1.4083$ as summarised in the fourth, fifth and sixth columns of Table 1 .

The $N=41$ ordered quarterly cash and cash equivalent balances comprising our Canam Group Inc. sample data were then divided into seven groups containing 6 or 7 observations

\footnotetext{
${ }^{12}$ Note how equation (35) shows that the Cramér-von Mises goodness of fit statistic, $T_{3}$, is based purely on the vertical distance between the hypothesised distribution function and the empirical distribution function as derived from the ordered random sample of cash and cash equivalent balance observations, $w_{1}, w_{2}, w_{3}, \ldots, w_{N}$ (Mood, Graybill and Boes $(1974,286-287)$. Thus, the determination of the test statistic, $T_{3}$, does not require differentiation of the likelihood function (as in maximum likelihood) or the estimation of possibly non-convergent moments (as with the Generalised Method of Moments).
} 
each and the Chi-square goodness of fit test applied on the assumption that the cash and cash equivalent balances are drawn from the probability density (25) with the above parameter values. Since our analysis is based on the estimation of three composite parameters, the computed Chi-square goodness of fit statistic summarised in the penultimate column of Table 1 - namely, $\chi^{2}=1.5806$ - will possess $(7-4)=3$ degrees of freedom (Walker 1940, 263; Conover 1980, 191). This in turn shows that the Canam Group Inc. cash and cash equivalent balance data are strongly compatible with the probability density (25). Here, the first panel of Figure 1 provides a graphical representation of the difference between the Pearson Type IV probability distribution function for the Canam Group Inc. based on the above parameter

\section{INSERT FIGURE ONE ABOUT HERE}

values and the actual (that is, empirical) probability distribution function. The second panel of Figure 1 is a graph of the probability density for the Canam Group Inc. normalised cash and cash equivalent balance data with the above parameter values. This latter graph depicts the normalised Canam Group Inc. cash and cash equivalent balances in terms of a highly skewed and highly leptokurtic probability density. These results are in direct contrast to the Jarque-Bera statistic for the Canam Group Inc. sample cash and cash equivalent balance data which amounts to $J B=82.0678$ as summarised in the final column of Table 1 . Since the Jarque-Bera statistic is asymptotically distributed as a Chi-square variate with two degrees of freedom it necessarily follows that a test statistic of this magnitude is highly incompatible with the hypothesis that the Canam Group Inc. cash and cash equivalent balances evolve in terms of the Gaussian probability density. ${ }^{13}$

\footnotetext{
${ }^{13}$ Simulation results summarised by Jones and Pewsey $(2009,772-774)$ show that the Jarque-Bera test "has the best overall performance" in comparison with six other widely used tests of compatibility with the Gaussian probability density.
} 
Data and empirical results for the other corporations summarised in Table 1 are to be similarly interpreted. Note in particular how all but four of the 100 corporations return Chisquare goodness of fit test statistics that are generally well below the upper $5 \%$ tail of the Chi-square density with three degrees of freedom (the exceptions being Akorn Inc., Alliant Energy Corp., Oshkosh Corp. and Span-America Medical Systems). This indicates that the cash and cash equivalent balances for the corporations summarised in Table 1 are strongly compatible with the probability density (25). In contrast, 59 (that is, nearly $60 \%$ ) of the 100 corporations comprising our sample have Jarque-Bera test statistics which fall above the upper 5\% tail of the Chi-square density with two degrees of freedom. This in turn shows it is highly unlikely the cash and cash equivalent balances for the sampled corporations are compatible with the pure random walk assumption on which the Miller and Orr (1966) and many subsequent cash management models have been based.

\section{Summary Conclusions}

Miller and Orr (1966) determine optimal cash balance policies under the assumption that cash balances evolve in terms of a pure random walk. The present paper develops a hyperbolic model under which cash balances evolve in terms of the Pearson Type IV probability density. The moments for the Type IV are in general undefined. Moreover, maximum likelihood parameter estimation is compromised by the non-algebraic nature of the Type IV normalising constant. We thus implement parameter estimation using the $\chi^{2}$ minimum method as summarised by Cramér (1946, 426-427). Our empirical analysis shows that the Type IV probability density is strongly compatible with the quarterly cash flow data of a randomly selected sample of 100 large U.S. corporations. In contrast, $60 \%$ of the corporations return Jarque-Bera test statistics which are not consistent with the pure random walk assumption on 
which the Miller and Orr (1966) and many subsequent cash management models have been based. 
Table 1. Parameter estimates for 100 randomly selected U.S. corporations based on the hyperbolic cash balance model

\begin{tabular}{|c|c|c|c|c|c|c|c|c|}
\hline CORPORATION & TIME PERIOD & $\mathrm{N}$ & $\xi_{1}$ & $\xi_{2}$ & $\xi_{3}$ & $\begin{array}{l}\text { RAMER } \\
T_{3}\end{array}$ & $\begin{array}{l}\text { CHI- } \\
\text { SQ(3) }\end{array}$ & $\mathrm{J}-\mathrm{B}(2)$ \\
\hline ACADIA PHARMACEUTICALS & 03/2007-09/2017 & 43 & 0.0277 & -6.1855 & 1.3498 & 0.1709 & 4.1180 & 11.5942 \\
\hline ACETO CORP & 09/2006-09/2017 & 45 & 0.0540 & -34.0643 & 2.9299 & 0.0325 & 3.3853 & 8.5604 \\
\hline AEROJET ROCKETDYNE & 02/2007-09/2017 & 43 & 0.3998 & -0.4779 & 1.4833 & 0.0275 & 1.3670 & 15.6684 \\
\hline AGILYSYS INC. & 06/2007-09/2017 & 42 & 0.0461 & -1.5214 & 1.6201 & 0.0449 & 2.3400 & 962.4622 \\
\hline AKORN INC. & $06 / 2007-09 / 2017$ & 43 & 0.0979 & -13.8725 & 1.8250 & 0.1179 & 8.9431 & 12.8276 \\
\hline ALLIANT ENERGY CORP. & 03/2007-09/2017 & 43 & 0.0755 & -13.5335 & 1.6815 & 0.1193 & 11.0718 & 75.9117 \\
\hline ALTRIA GROUP INC. & $03 / 2006-09 / 2017$ & 47 & 0.0298 & -14.3202 & 6.4552 & 0.0231 & 2.0228 & 4.3408 \\
\hline AMGEN INC. & 03/2007-09/2017 & 43 & 0.3547 & -0.2540 & 1.3199 & 0.0216 & 1.2178 & 15.2959 \\
\hline AMERICAN VANGUARD CORP. & 03/2007-09/217 & 43 & 0.2197 & -1.1175 & 1.3291 & 0.0470 & 0.9529 & 87.1017 \\
\hline ANALOGIC CORP. & 10/2006-10/2017 & 45 & 0.0860 & -27.6530 & 14.8278 & 0.0933 & 2.5190 & 14.8278 \\
\hline ANDREA ELECTRONICS CORP. & 03/2007-09/2017 & 43 & 0.6225 & -5.0205 & 2.5259 & 0.0703 & 4.0552 & 41.9010 \\
\hline APPLE INC. & $12 / 2006-09 / 2017$ & 44 & 0.0057 & -139.82 & 14.7779 & 0.0244 & 2.2703 & 2.1376 \\
\hline APPLIED MATE & $01 / 2007-09 / 2017$ & 44 & 0.0661 & -29.0350 & 2.2432 & 0.0753 & 1.8366 & 12.9630 \\
\hline JTS CORP. & $12 / 20$ & 44 & 0.0488 & -315.033 & 64.6422 & 0.0212 & 0.8033 & 2.2079 \\
\hline ASTRONOVA INC. & $12 / 2006-09 / 2017$ & 44 & 0.0558 & -147.715 & 22.0870 & 0.0401 & 1.5747 & 64.6788 \\
\hline BERKSHIRE HATH ENERGY & $03 / 2009-09 / 2017$ & 35 & 0.0049 & -113.501 & 12.1684 & 0.0598 & 3.4859 & 3.0235 \\
\hline BIG LOTS INC. & $04 / 2007-10 / 2017$ & 43 & 0.0552 & -0.3255 & 1.0587 & 0.0599 & 1.5834 & 69.8294 \\
\hline BRINKER INTERNATIONAL & 09/2006-09/2017 & 45 & 0.0857 & -0.4335 & 1.2238 & 0.0301 & 2.0263 & 354.1603 \\
\hline CSP INC. & $12 / 2006-09 / 2017$ & 44 & -0.0470 & 185.4054 & 65.8848 & 0.0241 & 0.8464 & 0.9154 \\
\hline CANAM GROUP INC. & 03/2007-03/2017 & 41 & 0.1132 & -4.3424 & 1.4083 & 0.0225 & 1.5806 & 82.0678 \\
\hline CASEYS GENERAL STORES & 01/2009-10/2017 & 36 & 0.0053 & -82.4807 & 9.1315 & 0.0573 & 2.0413 & 2.8163 \\
\hline CINTAS CORP. & 08/2007-11/2017 & 42 & 0.0997 & -151.311 & 53.6387 & 0.0375 & 1.1153 & 14.3631 \\
\hline COCA-COLA BTLNG CONS. & $03 / 20$ & 43 & 0.0233 & -25.9754 & 4.0426 & 0.0308 & 1.0990 & 11.5381 \\
\hline CORCEPT THERAPEUTICS INC. & $03 / 2007-09 / 2017$ & 43 & 0.0199 & -110.915 & 7.9684 & 0.0443 & 2.4728 & 15.6975 \\
\hline CRACKER BARREL OLD & $10 / 2006-10 / 2017$ & 45 & 0.5587 & -27.6000 & 6.8594 & 0.1054 & 0.7024 & 2.1760 \\
\hline DAIMLER AG & 03/2007-09/2017 & 43 & 0.4947 & -0.0426 & 1.1365 & 0.0410 & 2.7943 & 66.0517 \\
\hline DATA I/O CORP. & $03 / 2007-09 / 2017$ & 43 & 0.1141 & -33.47 & 8.4670 & 0.0889 & 4.9746 & 8.4670 \\
\hline
\end{tabular}




\begin{tabular}{|c|c|c|c|c|c|c|c|c|}
\hline DGSE COMPANIES INC. & 03/2007-09/2017 & 43 & 0.8769 & -3.8177 & 2.0924 & 0.0187 & 0.9726 & 37.4748 \\
\hline EASTERN COMPANY & 03/2007-09/2017 & 43 & -0.1169 & 18.2228 & 38.9423 & 0.0553 & 1.8300 & 2.5407 \\
\hline EMC INSURANCE GROUP INC. & 03/2007-09/2017 & 43 & 1.2428 & -102.86 & 36.7871 & 0.0165 & 0.7657 & 0.1454 \\
\hline EMERSON RADIO CORP. & 06/2007-09/2017 & 42 & 0.0352 & -19.8554 & 14.1693 & 0.0591 & 1.5816 & 0.8951 \\
\hline EW SCRIPPS-CL A & 03/2007-09/2017 & 43 & -0.0496 & 0.5968 & 2.4488 & 0.0675 & 2.1520 & 2.5767 \\
\hline FINNING INTERNATIONAL INC. & 03/2007-09/2017 & 43 & 0.0658 & -4.2306 & 2.3311 & 0.0684 & 1.7801 & 6.4167 \\
\hline FLANIGANS ENTERPRISES INC. & $12 / 2006-09 / 2017$ & 44 & 0.2212 & -16.3417 & 20.7128 & 0.0253 & 0.7583 & 1.2491 \\
\hline FOOT LOCKER INC. & 04/2007-10/2017 & 43 & -0.1692 & 44.9040 & 4.3248 & 0.0430 & 2.2867 & 3.5754 \\
\hline FOSTER (LB) CO. & 03/2007-09/2017 & 43 & -0.1869 & 11.6691 & 25.8374 & 0.0690 & 1.6944 & 2.3934 \\
\hline FRANKLIN ELECTRIC CO INC. & 03/2007-09/2017 & 43 & -0.1091 & 81.5089 & 163.5250 & 0.0422 & 2.0594 & 2.0515 \\
\hline FUJITSU LTD & 03/2008-09/2017 & 39 & 0.2082 & -2.4295 & 1.9612 & 0.0184 & 2.8022 & 25.6981 \\
\hline GENERAL DYNAMICS CORP. & 03/2007-09/2017 & 43 & 0.0622 & -11.3943 & 3.8971 & 0.0397 & 2.5626 & 4.6642 \\
\hline GENESCO INC. & 04/2007-10/2017 & 43 & 0.0175 & -26.7257 & 8.9822 & 0.0641 & 3.7291 & 25.1982 \\
\hline GENUINE PARTS CO. & 03/2006-09/2017 & 47 & 0.0539 & -34.9415 & 2.4520 & 0.0496 & 3.0124 & 29.1638 \\
\hline GIGA-TRONICS INC. & 06/2007-09/2017 & 42 & 0.2063 & -1.6336 & 2.2516 & 0.0273 & 2.2736 & 3.2086 \\
\hline GOODYEAR TIRE \& RUBBER & 03/2007-09/2017 & 43 & -2.1750 & 0.1800 & 2.1697 & 0.0262 & 2.4084 & 0.1403 \\
\hline GULF POWER CO. & 03/2007-09/2017 & 43 & 0.0534 & -1.7370 & 1.7137 & 0.0307 & 1.8776 & 220.9687 \\
\hline HEALTHCARE SERVICES GR. & 03/2007-09/2017 & 43 & 0.0161 & -32.816 & 8.1832 & 0.0262 & 3.5993 & 2.0205 \\
\hline HALLIBURTON CO. & 03/2007-12/2017 & 44 & 0.4043 & -0.0520 & 1.0290 & 0.0353 & 0.6378 & 448.6742 \\
\hline HEICO CORP. & 01/2007-10/2017 & 44 & 0.0439 & -26.4516 & 4.0932 & 0.0406 & 1.7089 & 7.7347 \\
\hline HENRY (JACK) \& ASSOCIATES & 09/2006-09/2017 & 45 & 0.0145 & -35.336 & 2.6035 & 0.0405 & 1.3560 & 6.5445 \\
\hline HUTCHINSON TECH INC. & $12 / 2006-06 / 2016$ & 39 & 0.0335 & -9.1025 & 1.7381 & 0.0471 & 1.1018 & 42.9192 \\
\hline IKONICS CORP. & 03/2007-09/2017 & 43 & 0.8030 & -33.0607 & 2.3802 & 0.0370 & 2.8896 & 17.3923 \\
\hline INTEGRATED DEVICE TECH & 06/2007-09/2017 & 42 & 0.1392 & -27.571 & 4.2365 & 0.0270 & 0.5888 & 6.2852 \\
\hline INTERPUBLIC GROUP & 03/2007-09/2017 & 43 & -0.0318 & 274.3779 & 28.7399 & 0.0917 & 6.5550 & 1.0867 \\
\hline KEY TRONIC CORP. & 09/2006-09/2017 & 45 & 0.7686 & -3.6344 & 1.7395 & 0.0289 & 0.4178 & 244.8249 \\
\hline KIRIN HOLDINGS CO LTD & $12 / 2008-09 / 2017$ & 36 & 0.1125 & -30.7298 & 4.5608 & 0.0339 & 2.1280 & 6.4996 \\
\hline KLA-TENCOR CORP. & 09/2007-09/2017 & 41 & 0.2069 & -29.1773 & 7.2131 & 0.0380 & 1.5139 & 4.5939 \\
\hline KONINKLIJKE PHILIPS NV. & 03/2007-09/2017 & 43 & 0.1865 & -34.4605 & 5.9129 & 0.0360 & 2.4982 & 17.5797 \\
\hline LEE ENTERPRISES INC. & $12 / 2006-06 / 2017$ & 43 & 0.0288 & -164.307 & 33.8190 & 0.0208 & 1.2827 & 0.0877 \\
\hline LEGGETT \& PLATT INC. & 03/2007-12/2017 & 43 & -0.0600 & 345.6526 & 13.8374 & 0.1387 & 3.4057 & 14.8331 \\
\hline LOBLAW COMPANIES LTD & 03/2007-09/2017 & 43 & 0.0450 & -176.046 & 35.9884 & 0.0555 & 3.1320 & 21.5609 \\
\hline
\end{tabular}




\begin{tabular}{|c|c|c|c|c|c|c|c|c|}
\hline LSI INDUSTRIES INC. & 06/2008-09/2017 & 38 & 0.1837 & -1.5390 & 2.0614 & 0.0439 & 0.5132 & 3.2986 \\
\hline LYDALL INC. & 03/2007-09/2017 & 43 & -0.0085 & 319.7804 & 12.7798 & 0.1455 & 6.7158 & 4.3910 \\
\hline MCCORMICK \& CO INC. & 02/2007-08/2017 & 43 & 0.0124 & -19.4440 & 5.3308 & 0.0366 & 2.1190 & 3.4995 \\
\hline MCDONALD'S CORP. & 03/2007-09/2017 & 43 & 0.0508 & -50.0332 & 15.4377 & 0.1188 & 4.4792 & 799.1839 \\
\hline MAXIM INTEGR PRODUCTS & 09/2006-09/2017 & 45 & 0.1211 & -16.9063 & 4.7375 & 0.0523 & 2.0351 & 3.8425 \\
\hline MENTOR GRAPHICS CORP. & 04/2007-01/2017 & 40 & 0.0101 & -100.503 & 2.1369 & 0.0330 & 2.1388 & 9.6152 \\
\hline MICROSOFT CORP. & 09/2007-09/2017 & 41 & 0.0601 & -2.4824 & 2.8711 & 0.0165 & 1.7322 & 4.0352 \\
\hline NANOMETRICS INC. & 03/2007-09/2017 & 43 & 0.0141 & -60.7688 & 9.6792 & 0.0762 & 1.4255 & 3.7728 \\
\hline NOBLE CORP. & 03/2007-09/2017 & 43 & 0.3165 & -9.1791 & 2.5255 & 0.0693 & 4.3311 & 7.4020 \\
\hline NORTHWESTERN CORP. & 03/2007-09/2017 & 43 & 0.1169 & -12.8764 & 1.7410 & 0.0233 & 0.2723 & 744.8751 \\
\hline OPPENHEIMER HOLDINGS INC. & 03/2007-09/2017 & 43 & 0.0880 & -193.545 & 20.1505 & 0.0728 & 3.7984 & 2.7030 \\
\hline OSHKOSH CORP. & $12 / 2006-09 / 2017$ & 44 & 0.0189 & -182.582 & 3.3674 & 0.2234 & 20.3553 & 1.6223 \\
\hline OWENS CORNING & 03/2007-09/2017 & 43 & 0.1580 & -7.2833 & 1.3356 & 0.0465 & 1.0783 & 103.1805 \\
\hline OXFORD INDUSTRIES INC. & 07/2008-10/2017 & 38 & 0.1976 & -3.5944 & 1.2317 & 0.0436 & 1.6146 & 64.7446 \\
\hline PAYCHEX INC. & 08/2006-11/2017 & 46 & 0.0501 & -25.7508 & 4.0249 & 0.0451 & 2.6914 & 6.5155 \\
\hline PEPSICO INC. & 03/2007-09/2017 & 43 & 0.0890 & -76.2034 & 153.0624 & 0.0726 & 7.1928 & 3.5141 \\
\hline PPL CORP. & 03/2007-09/2017 & 43 & 0.3094 & -1.0944 & 1.4972 & 0.0214 & 1.6845 & 274.7501 \\
\hline PRICE (T. ROWE) GROUP & 03/2007-09/2017 & 43 & 0.0120 & -15.9541 & 14.0663 & 0.0738 & 4.2193 & 3.0406 \\
\hline PTC INC. & $12 / 2004-12 / 2017$ & 53 & 1.2944 & -0.1496 & 1.2611 & 0.0317 & 0.8696 & 35.0366 \\
\hline QUALITY SYSTEMS INC. & 06/2007-09/2017 & 42 & -0.0114 & 108.4728 & 4.5960 & 0.0500 & 2.1098 & 3.4608 \\
\hline RADIAN GROUP INC. & 03/2008-09/2017 & 39 & 0.0236 & -29.1533 & 2.8095 & 0.0525 & 2.2214 & 79.1792 \\
\hline RICHARDSON ELECTRONICS & 08/2007-11/2017 & 42 & 0.0203 & -46.2318 & 3.8291 & 0.0258 & 0.8309 & 38.8557 \\
\hline ROCKY MOUNTAIN CHOC. & 05/2007-11/2017 & 43 & 3.3289 & -0.3278 & 2.4584 & 0.0192 & 1.3254 & 0.6397 \\
\hline ROYAL HAWAIIAN ORCHARDS & 03/2007-09/2017 & 43 & 0.9963 & -14.7556 & 1.2903 & 0.0236 & 2.2708 & 275.7990 \\
\hline ROYAL GOLD INC. & 09/2008-09.2017 & 37 & -0.1192 & 4.6093 & 11.2055 & 0.0400 & 3.0921 & 1.5443 \\
\hline SCANA CORP. & 03/2006-09/2017 & 47 & 0.1401 & -1.9414 & 1.5970 & 0.0282 & 1.9633 & 1071.2437 \\
\hline SCHULMAN (A.) INC. & 11/2006-11/2017 & 45 & 0.0420 & -135.361 & 36.8440 & 0.0744 & 5.0675 & 12.5609 \\
\hline SEI INVESTMENTS CO. & 03/2007-09/2017 & 43 & 0.0162 & -169.328 & 25.0627 & 0.0335 & 4.1247 & 1.7470 \\
\hline SKF AB & 03/2007-09/2017 & 43 & 0.1250 & -27.6063 & 11.4395 & 0.0405 & 1.6883 & 1.3254 \\
\hline SPAN-AMERICA MEDICAL SYS. & $12 / 2006-03 / 2017$ & 42 & 0.4193 & -19.1215 & 1.9954 & 0.1062 & 15.1206 & 7.2900 \\
\hline SPX CORP. & 03/2007-09/2017 & 43 & -5.8932 & 0.0863 & 1.1857 & 0.0611 & 1.7746 & 6.8533 \\
\hline EPAN CO. & $7-09 / 2017$ & 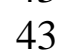 & 0.0490 & -42.0673 & 12.2181 & 0.0792 & 4.1552 & 3.2691 \\
\hline
\end{tabular}




$\begin{array}{lcccccccc}\text { TAT TECHNOLOGIES LTD } & 09 / 2008-09 / 2017 & 37 & 0.4781 & -4.8228 & 29.4054 & 0.0269 & 2.1137 & 0.2613 \\ \text { TECH DATA CORP. } & 03 / 2007-09 / 2017 & 43 & 0.0297 & -9.5448 & 2.7851 & 0.0279 & 4.2645 & \mathbf{1 9 6 . 7 8 8 9} \\ \text { TELUS CORP. } & 03 / 2007-09 / 2017 & 43 & 0.0076 & -388.745 & 1.1258 & 0.1081 & 7.6082 & \mathbf{3 6 6 . 6 7 3 8} \\ \text { TRANSCONTINEN RLTY INVS. } & 03 / 2007-09 / 2017 & 43 & 0.1229 & -2.7021 & 1.6853 & 0.0304 & 1.6351 & \mathbf{1 2 1 . 1 2 8 4} \\ \text { VALUE LINE INC. } & 04 / 2008-10 / 2017 & 39 & 0.1295 & -5.3450 & 1.3385 & 0.0403 & 0.4653 & \mathbf{5 5 . 6 1 0 8} \\ \text { WD-40 CO. } & 11 / 2006-11 / 2017 & 45 & 0.0147 & -256.582 & 37.3762 & 0.0417 & 2.2625 & 0.7255 \\ \text { WEC ENERGY GROUP INC. } & 03 / 2007-09 / 2017 & 43 & 0.0452 & -0.9232 & 1.1368 & 0.0402 & 2.8656 & \mathbf{9 4 9 . 6 5 6 8} \\ \text { WHITE MTNS INS GROUP LTD } & 03 / 2007-09 / 2017 & 43 & 0.5352 & -19.3912 & 5.4107 & 0.0556 & 1.9821 & 3.7828 \\ \text { WORLDS INC. } & 03 / 2006-09 / 2017 & 47 & 0.1017 & -23.0799 & 2.0823 & 0.0566 & 4.2054 & \mathbf{3 0 . 1 4 8 3} \\ \text { MEDIAN } & & & & & & & & \\ & & 43 & 0.0555 & -14.5379 & 3.8631 & 0.0414 & 2.1118 & \mathbf{8 . 1 0 0 9}\end{array}$

Notes: Column one provides the identities of the 100 U.S. corporations on which the empirical analysis is based. Columns two and three summarise the period and number of quarterly cash and cash equivalent balance observations (Compustat item 74) over which the parameter estimation occurs. Columns four, five and six summarise the composite parameter estimates, $\xi_{1} \equiv \frac{k_{2}}{k_{0}}$, $\xi_{2} \equiv \frac{2 \sqrt{2}}{k_{2}}\left(A-\frac{\sqrt{2} B k_{0}}{k_{2}}\right)$ and $\xi_{3} \equiv \frac{1}{2}\left(1-\frac{4 B}{k_{2}^{2}}\right)$, respectively. Column seven summarises the minimised Cramér-von Mises goodness of fit statistic, $T_{3}$, associated with the $\chi^{2}$ minimum method. Column eight summarises the Chi-square goodness of fit statistic which is asymptotically distributed with three degrees of freedom. Column nine summarises the Jarque-Bera statistic which is asymptotically distributed with two degrees of freedom. Statistics in bold italics fall into the upper 5\% tail of the affected probability density. 
(a)

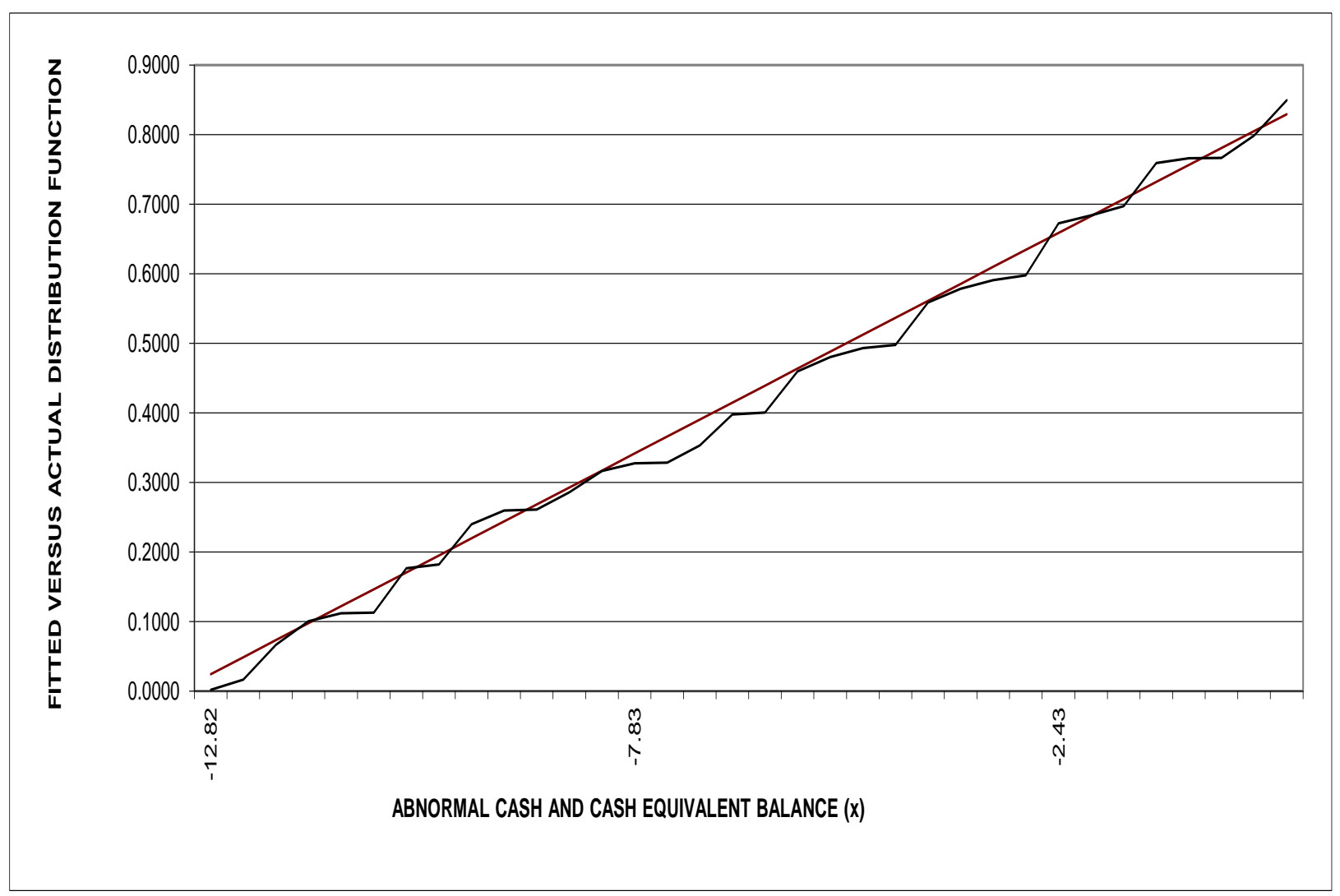

(b)

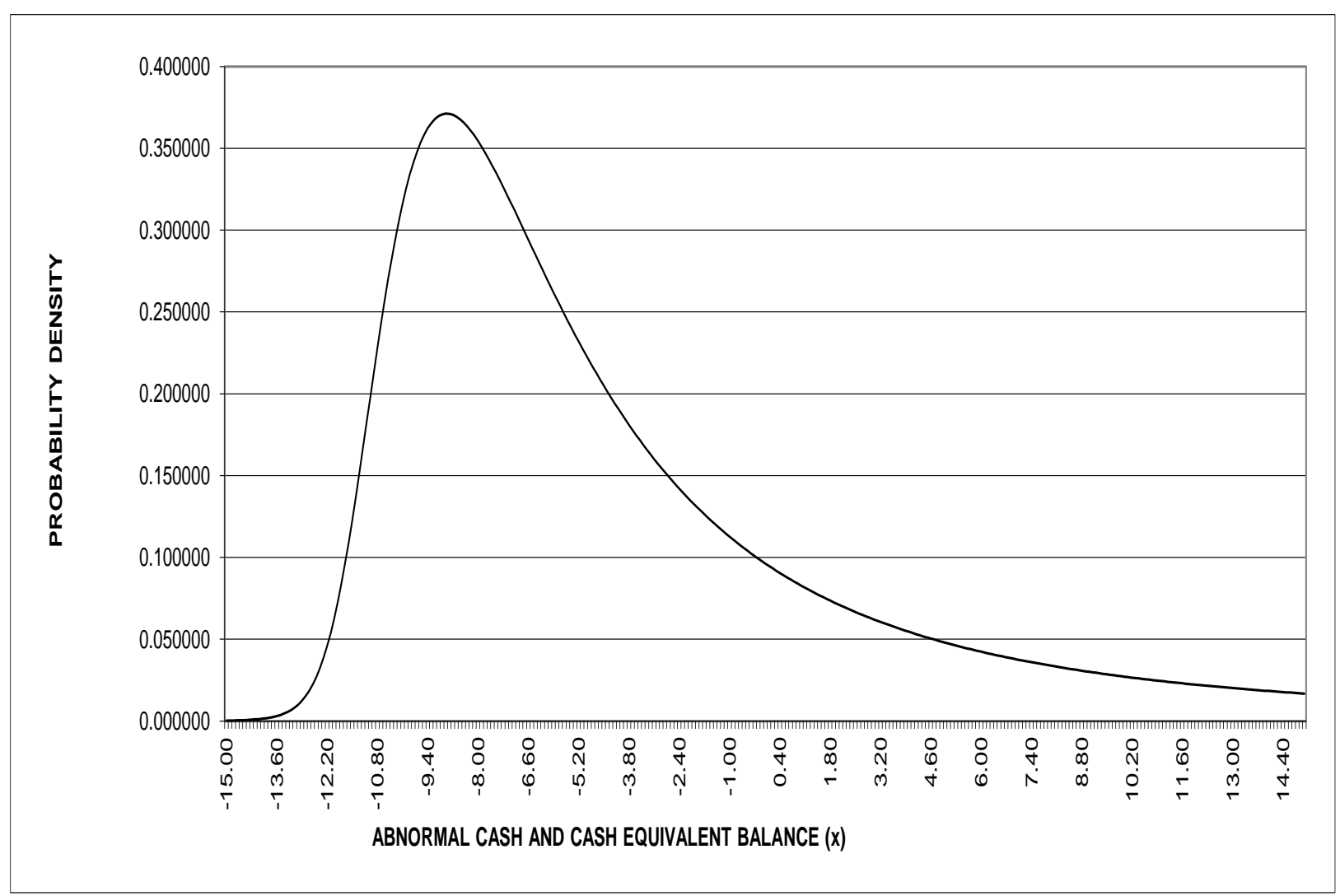


Figure 1. (a) Difference between the estimated Pearson Type IV distribution function for Canam Group Inc. quarterly cash and cash equivalent data with composite parameter values $\xi_{1} \equiv \frac{k_{2}}{k_{0}}=0.1132, \quad \xi_{2} \equiv \frac{2 \sqrt{2}}{k_{2}}\left(A-\frac{\sqrt{2} B k_{0}}{k_{2}}\right)=-4.3424 \quad$ and $\quad \xi_{3} \equiv \frac{1}{2}\left(1-\frac{4 B}{k_{2}^{2}}\right)=1.4083 \quad$ and the actual (that is, empirical) distribution function for Canam Group Inc. (b) Estimated Pearson Type IV probability density for Canam Group Inc. quarterly cash and cash equivalent data with the parameter values defined in panel (a). 


\section{References}

Abramowitz, M. and Stegun, I., 1964. Handbook of mathematical functions with formulas, graphs, and mathematical tables. Washington, DC: NBS Applied Mathematics Series 55, National Bureau of Standards.

Arnold, L. 1974. Stochastic differential equations. New York: Wiley.

Baccarin, S. 2009. Optimal impulse control for a multidimensional cash management system with generalized cost functions. European Journal of Operational Research, 196(1), 198206.

Bartlett,M. 1955. An introduction to stochastic processes. Cambridge: Cambridge University Press.

Berkson, J. 1980. Minimum chi-square, not maximum likelihood. Annals of Statistics, 8(3), 457-487.

Black, F. 1995. Interest rates as options. Journal of Finance, 50(5), 1371-1376.

Boyce, W. and DiPrima, R. 2005. Elementary differential equations and boundary value problems. New York: Wiley.

Carnahan, B., H. Luther and J. Wilkes. 1969. Applied numerical analysis. New York: Wiley.

Chen, J., Ma, D., Song X. and Tippett, M. 2017. Negative real interest rates. European Journal of Finance, 23(15), 1447-1467.

Conover, W. 1980. Practical Nonparametric Statistics. New York: Wiley.

Constantinides, G. (1976). Stochastic cash management with fixed and proportional transaction costs. Management Science, 22(12), 1320-1331.

Cox, D. and Miller, H. 1965. Theory of stochastic processes. London: Chapman and Hall.

Cox, J., Ingersoll, J. and Ross, S. 1985. A theory of the term structure of interest rates. Econometrica, 53(2), 385-407.

da Costa Moraes, M., Nagano, M., and Sobreiro, V. 2015. Stochastic cash flow management models: A literature review since the 1980s. in Guarnieri, P. (ed). Decision Models in Engineering and Management, Switzerland: Springer, 11-28.

Cramér, H. 1946. Mathematical methods of statistics. Princeton: Princeton University Press.

Daellenbach, H. 1971. A stochastic cash balance model with two sources of short-term funds. International Economic Review, 12(2), 250-256.

Eppen, G. and Fama, E. 1969. Cash balance and simple dynamic portfolio problems with proportional costs. International Economic Review, 10(2), 119-133. 
Frenkel, J. and Jovanovic, B. 1978. On transactions and precautionary demand for money. National Bureau of Economic Research Working Paper Series, No. 288. doi:10.3386/w0288

Gormley, F. and Meade, N. 2007. The utility of cash flow forecasts in the management of corporate cash balances. European Journal of Operational Research, 182(2), 923-935.

Grigelionis, B. 2013. Student's t-distribution and related stochastic processes. Heidelberg: Springer.

Guo, Q., Rhys, H., Song, X, and Tippett, M. 2016. The Friedman rule and inflation targeting. European Journal of Finance, 22(14), 1414-1434.

Hall, A. 2005. Generalized method of moments. Oxford University Press. Oxford.

Heinrich, J. 2004. A guide to the Pearson Type IV distribution. Note 6820, Collider Dectector at Fermilab, Fremilab, Batavia, Illinois.

Higson, A., Yoshikatsu, S., and Tippett, M. 2010. Organization size and the optimal investment in cash. IMA Journal of Management Mathematics, 21(1), 27-38.

Hinderer, K. and Waldmann, K. 2001. Cash management in a randomly varying environment. European Journal of Operational Research, 130(3), 468-485.

Jarque, C. and Bera, A. 1980. Efficient tests for normality, homoscedasticity and serial independence of regression residuals. Economics Letters, 6(3), 255-259.

Jones, M. and Pewsey, A. 2009. Sinh-arcsinh distributions. Biometrika, 96(4), 761-780.

Karlin, S., and H. Taylor. 1981. A second course in stochastic processes. London: Academic Press.

Kendall, M. and A. Stuart. 1977. Advanced theory of statistics: volume 1. London: Charles Griffin \& Company.

Kendall, M. and A. Stuart. 1979. Advanced theory of statistics: volume 2. London: Charles Griffin \& Company.

Keynes, J. 1936. The general theory of employment, interest and money. London: MacMillan and Company Ltd.

Leonenko, G. and Phillips, T. 2012. High-order approximation of Pearson diffusion process, Journal of Computational and Applied Mathematics, 236: 2853-2868.

Mallaris, A. 1989. Approaches to the cash management problem. Advances in financial planning and forecasting, 3 .

Merton, R. 1969. Lifetime portfolio selection under uncertainty: the continuous-time case. Review of Economics and Statistics, 51(3): 247-257. 
Miller, M. and Orr, D. 1966. A model of the demand for money by firms. Quarterly Journal of Economics, 80(3), 413-435.

Møller, J. and Madsen, H. 2010. From State Dependent Diffusion to Constant Diffusion in Stochastic Differential Equations by the Lamperti Transform. Kgs. Lyngby, Denmark: Technical University of Denmark, DTU Informatics, Building 321. (IMM-Technical Report2010-16).

Mood, A., Graybill, F. and Boes, D. 1974. Introduction to the theory of statistics. New York: McGraw-Hill.

Nagahara, Y. 1999, The PDF and CF of Pearson type IV distributions and the ML estimation of the parameters. Statistics \& Probability Letters, 43(3): 251-264.

Nelson, D. and Ramaswamy, K. 1990. Simple binomial processes as diffusion approximations in financial models. Review of Financial Studies, 3(3), 393-430.

Patinkin, D. 1965. Money, interest and prices. Evanston, Illinois: Harper \& Row.

Premachandra, I. 2004. A diffusion approximation model for managing cash in firms: An alternative approach to the Miller-Orr model. European Journal of Operational Research, 157(1), 218-226.

Shaw, W. and Schofield, M. 2015. A model of returns for the post-credit-crunch reality: hybrid Brownian motion with price feedback. Quantitative Finance, 15(6), 975-998.

Smith, G. 1986. A dynamic Baumol-Tobin model of money demand. Review of Economic Studies, 53(3), 465-469.

Tapiero, C. and Zuckerman, D. 1980. A note on the optimal control of a cash balance problem. Journal of Banking \& Finance, 4(4), 345-352.

Uhlenbeck, G. and L. Ornstein. 1930. On the theory of the Brownian motion. Physical Review 36(5): 823-841.

Vial, J. P. (1970). A continuous time model for the cash balance problem: Center for Operations Research \& Econometrics.

Walker, H. 1940. Degrees of freedom. Journal of Educational Psychology, 31(4), 253-269.

Wang Z., Xu, G., Zhao P., and Lu Z. 2018. The optimal cash holding models for stochastic cash management of continuous time. Journal of Industrial and Management Optimization, 14(1): 1-17.

Yao, J., Chen, M., \& Lu, H. 2006. A fuzzy stochastic single-period model for cash management. European Journal of Operational Research, 170(1), 72-90. 